\title{
Estimation of resistance force at steady-state sinkage for cylindrical wheel-typed lunar/ planetary exploration rovers with function of push-pull locomotion
}

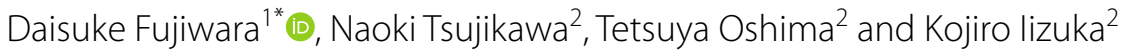

\begin{abstract}
Planetary exploration rovers have required a high traveling performance to overcome obstacles such as loose soil and rocks. Push-pull locomotion rovers is a unique scheme, like an inchworm, and it has high traveling performance on loose soil. Push-pull locomotion uses the resistance force by keeping a locked-wheel related to the ground, whereas the conventional rotational traveling uses the shear force from loose soil. The locked-wheel is a key factor for traveling in the push-pull scheme. Understanding the sinking behavior and its resistance force is useful information for estimating the rover's performance. Previous studies have reported the soil motion under the locked-wheel, the traction, and the traveling behavior of the rover. These studies were, however, limited to the investigation of the resistance force and amount of sinkage for the particular condition depending on the rover. Additionally, the locked-wheel sinks into the soil until it obtains the required force for supporting the other wheels' motion. How the amount of sinkage and resistance forces are generated at different wheel sizes and mass of an individual wheel has remained unclear, and its estimation method hasn't existed. This study, therefore, addresses the relationship between the sinkage and its resistance force, and we analyze and consider this relationship via the towing experiment and theoretical consideration. The results revealed that the sinkage reached a steady-state value and depended on the contact area and mass of each wheel, and the maximum resistance force also depends on this sinkage. Additionally, the estimation model did not capture the same trend as the experimental results when the wheel width changed, whereas, the model captured a relatively the same trend as the experimental result when the wheel mass and diameter changed.
\end{abstract}

Keywords: Push-pull locomotion, Resistance force, Loose soil, Terramechanics

\section{Introduction}

NASA, ESA, and JAXA have investigated past water activity or a clue to life on Martain or Lunar surfaces [1-5]. For investigating such planetary surfaces, surface mobility is one of the key factors for achieving a reliable mission, and many rovers have been developed in the world. The rover that is equipped with the function of a push-pull locomotion is a unique scheme, like an

\footnotetext{
*Correspondence: nb16107@shibaura-it.ac.jp

${ }^{1}$ Department of Functional Control Systems, Shibaura Institute

of Technology, 307, Fukasaku, Minuma-ku, Saitama 337-8570, Japan

Full list of author information is available at the end of the article
}

inchworm locomotion, and has a good traveling performance in the cylindrical wheel-typed rovers $[6,8,10]$. This scheme is a scheme that one side (front or rear) wheels are locked against ground, and they support a push or pull locomotion of the other side wheels using resistance force from the ground.

The autonomous traveling on a planet requires information between the wheels and soil. Understanding the interaction between a wheel and soil helps to design the traveling performance and model of a rover. The interaction between the locked-wheel and soil is the key factor for the push-pull locomotion rovers. 
For this reason, many researchers have investigated this interaction for each push-pull locomotion rover or wheel walking robot. Sybel et al. [7] investigated the resistance force of each locked-wheel for a wheel walking robot around the 1960s. In 1998, Andrade et al. tried to estimate the traveling performance of this locomotion by constructing the locked-wheel model against soil for Marsokhod rover [8]. Wong [9] investigated soil flow beneath a locked-wheel during towing. Creager et al. [10] also observed the soil flow under a wheel and measured the traction and sinkage of Scarab rover during traveling. According to Sybel et al. [7], the locked-wheel sinks into the soil with an increasing sinkage, and this sinkage reach to close value to the steady-state value. This phenomenon is also observed in our previous study using the testbed rover [11].

Slipping of a locked (supported) wheel is a negative effect on this locomotion, whereas the resistance force against soil increases with an increasing sinkage. A large resistance force helps to support the repositioning of the other wheels' motion. Analyzing especially the steadysinkage of the locked-wheel can lead to understanding the maximum resistance force. This analysis can contribute to constructing the accurate model for estimating the behavior of the locked-wheel and push-pull locomotion rovers. Although many studies have investigated the locked-wheel phenomenon and the traveling performance of push-pull locomotion, the amount of sinkage and its resistance force of each locked-wheel at different wheel seize and mass is yet to be determined. Additionally, the estimation model has not been developed.

This paper firstly aims to investigate sinkage and its resistance force of each locked-wheel on loose soil during towing through an experiment. Furthermore, this paper considers theoretically this phenomenon based on the terramechanics and soil mechanics and tries to estimate the steady-state sinkage and resistance force of each locked-wheel in the next.

\section{Push-pull locomotion traveling mechanism}

Figure 1 shows the schematic view of push-pull locomtoion testbed rover that is owned by our laboratory, and Fig. 2 also shows actual images of the traveling experiment on the surface with slope using this testbed.

The front wheels of the rover are firstly fixed to the ground at the initial position (Fig. 2a). Next, the rover can shrink its wheel-base using the resistance force of the front wheels (Fig. 2a-b). In the next, the rear wheels of the rover are fixed to the ground. Then, the rover extends its wheel-base using the resistance of the rear wheels (Fig. $2 \mathrm{~b}-\mathrm{c}$ ). The rover can move to forward direction by repeating this scheme.

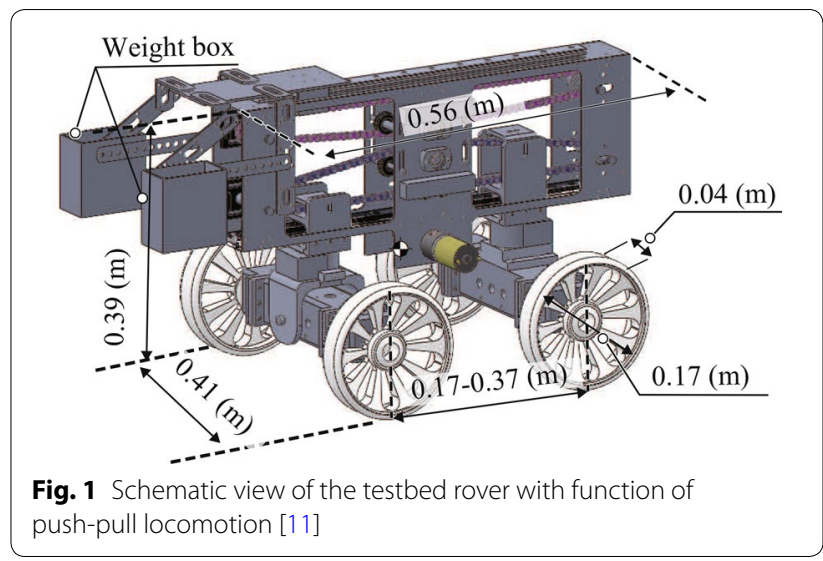

When the required resistance force that supports the other wheels' motion is small, the necessary accumulated soil behind the wheels is small, whereas the locked-wheel needs large accumulated soil that supports the other wheel's motion when the required force is large.

\section{The behavior of the locked-wheel}

As mentioned earlier, when the push-pull locomotion rover moves, the rover uses the resistance force generated by keeping the wheel related to the ground. When the resistance force generated by sinkage that depends on a vertical load of the wheel is less, the wheel sinks into the soil until the required resistance force rises.

This section describes the force component of the total resistance force and sinking mechanism of the locked-wheel.

\section{Resistance force}

According to Wong's study [9], when the locked-wheel acts on the soil, a wedge-shaped soil (area $A$ ) is formed in front of the wheel, and it pushes the soil mass area $B$, behaving like a bulldozing blade. Based on Wong's study [9], this study assumes a virtual plane between soilwedge area $A$ and $B$ and assumes that the soil-wedge area $A$ moves together with the wheel and pushes soil-wedge area $B$. As shown in Fig. 3, this paper consider that the resistance force consists of five forces as follows:

$$
F_{\text {total }}=F_{1}+F_{2}+F_{3}+F_{4}+F_{5}
$$

where, $F_{1}$ is the passive earth force of area $B$, which is calculated as the force of a virtual plate. $F_{2}$ is the shear force under the soil wedge of area $A . F_{3}$ is the side friction force in area A. $F_{4}$ is the friction force on the side surface of the wheel, and $F_{5}$ is the friction force between the wheel surface and soil. In this study, the wheel for the experiment has a smooth side surface; therefore, the friction force $F_{4}$ is expected relatively small. Hence, force $F_{4}$ is negligible. 

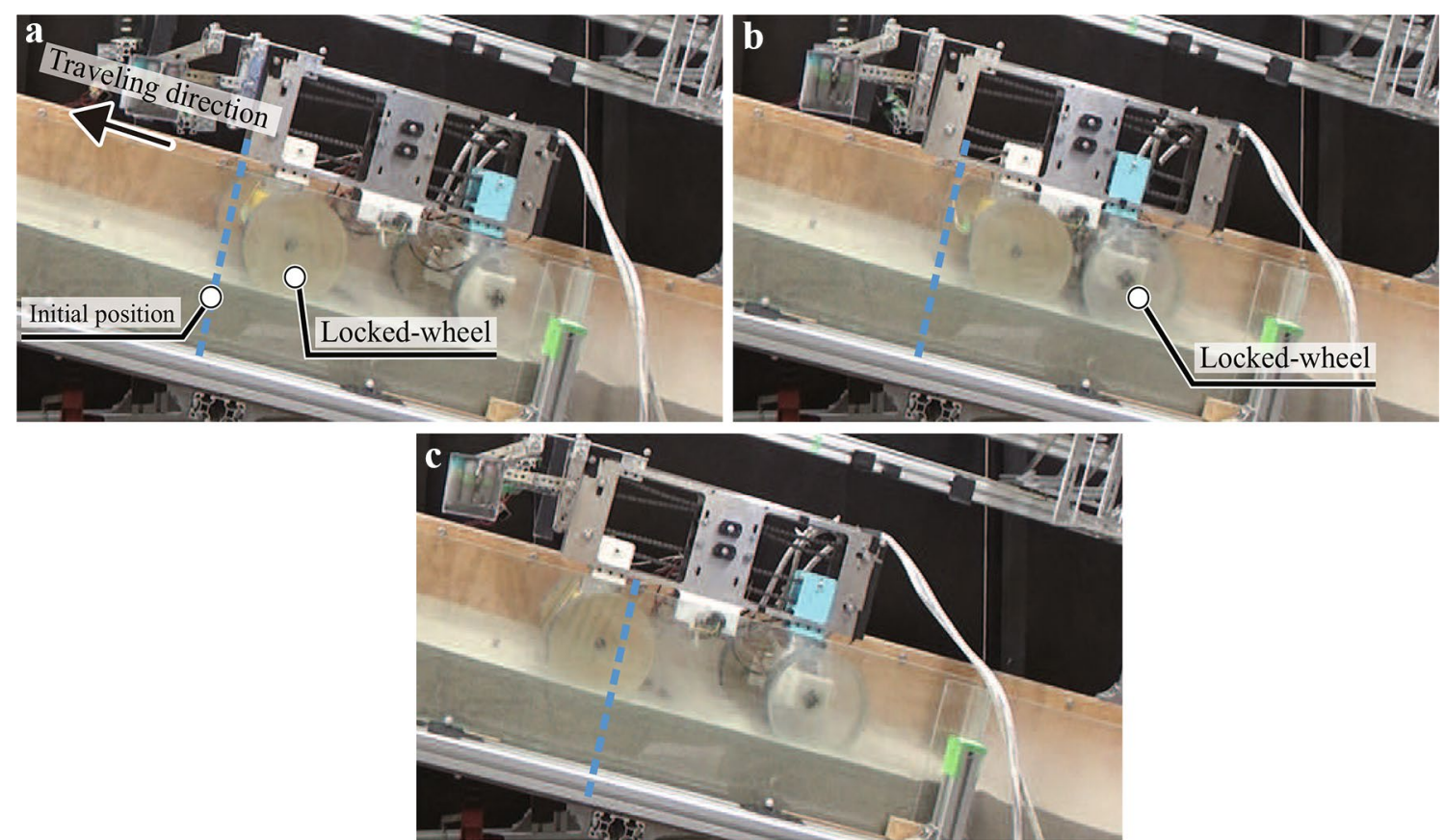

Fig. 2 Actual image of the traveling experiment on the soil. The rover firstly shrinks its wheel-base, and the front wheel is fixed to the ground and supports the rear wheels' motion $(\mathbf{a}-\mathbf{b})$. Next, the rover extends its wheel-base, and the rear wheel is also fixed to the ground and supports the front wheels' motion $(\mathbf{b}-\mathbf{c})$

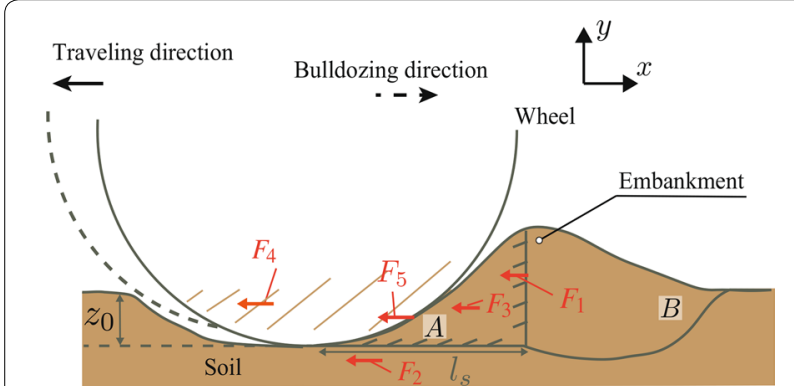

Fig. 3 Locked-wheel on the soil surface based on Wong's observation [9]. The soil wedge (area A) beneath the wheel is assumed to move together with the wheel. The surface between soil wedge areas $A$ and $B$ is assumed as a virtual surface

$z_{0}$ indicates the sinkage of the wheel, and it increases depending on an increasing towing distance.

\section{Wheel sinkage based on terramechanics theory}

Terramechanics studies defined the interaction between a wheel and soil. In 1969, Bekker defined the pressure-sinkage relationship of a plate as shown in Fig. 4. According to Bekker [12], the normal stress $p(z)$ acts on a plate when a plate sinks into loose soil as shown in Eq. (2).

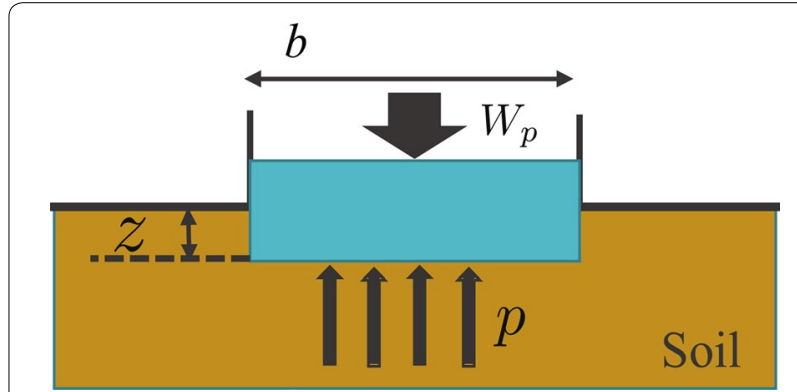

Fig. 4 Relationship between the plate and soil

$$
p(z)=\left(\frac{k_{c}}{b}+k_{\phi}\right) z^{n}
$$

where $k_{c}, k_{\phi}, n$, are the pressure-sinkage parameters that depend on soil types. $b$ indicates the width of a rectangular contact area of a plate.

Additionally, Bekker defined the rigid wheel-soil interaction model on loose soil based on the pressuresinkage model as shown in Fig. 5. The phenomenon of a wheel differs from a plate because sinkage varies in its position. The sinkage under the wheel is large, whereas the sinkage that is close to the surface of the contact area is small. The equilibrium equations for the vertical 


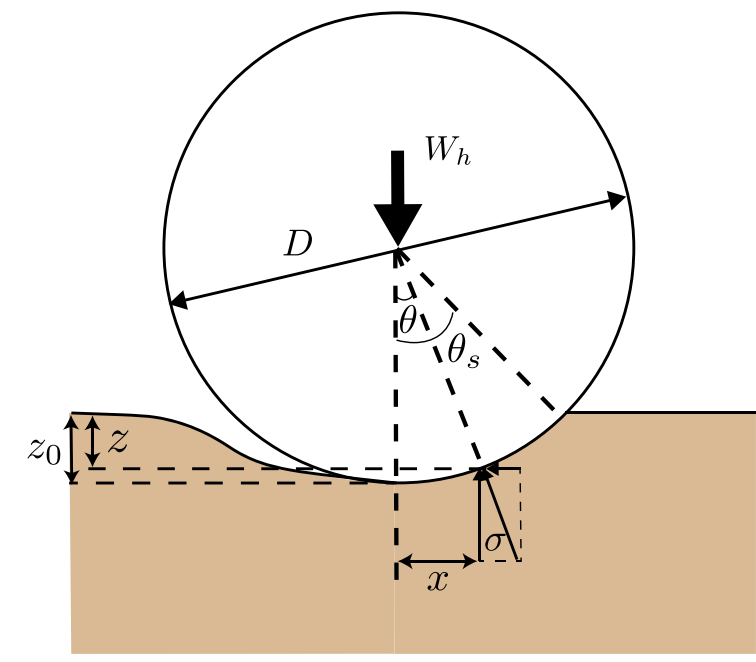

Fig. 5 Wheel-soil interaction on loose soil [12] direction of a towed rigid wheel can be writtern as follows Eq. (3):

$$
W_{h}=w_{w} \int_{0}^{\theta_{s}} \sigma r \cos \theta d \theta
$$

where $\sigma$ is the nromal pressure. $w_{w}$ and $r$ are the wheel width and radius. $W_{h}$ is the wheel weight. $\theta_{s}$ is the contact angle. The normal pressure $\sigma$ acting on the wheel rim is assumed that it is equal to the normal pressure $p$ beneath the plate at the same depth $\mathrm{z}$. Hence, $\sigma r \cos \theta d \theta$ equals to $p d x$. Using the pressure-sinkage relationship Eq. (2), the equilibrium equation for the vertical direction is as follows:

$$
\begin{aligned}
W_{h} & =-w_{w} \int_{0}^{z_{0}} p(x) d x \\
& =-w_{w} \int_{0}^{z_{0}}\left(\frac{k_{c}}{w_{w}}+k_{\phi}\right) z^{n} d x
\end{aligned}
$$

where $z_{0}$ is the sinkage. When the wheel sinkage is small, from the geometry shown in Fig. 5, the position $x$ is as follows:

$$
\begin{aligned}
x^{2} & =\left[D-\left(z_{0}-z\right)\right]\left(z_{0}-z\right) \\
& =D\left(z_{0}-z\right)
\end{aligned}
$$

where $D$ is the wheel diameter.

$$
2 x d x=-D d z
$$

Then, substituting Eq. (6) into Eq. (4).

$$
W_{h}=w_{w}\left(\frac{k_{c}}{w_{w}}+k_{\phi}\right) \int_{0}^{z_{0}}\left(\frac{z^{n} \sqrt{D}}{2 \sqrt{\left(z_{0}-z\right)}}\right) d z
$$

Then, using $z_{0}-z=t^{2}$, then $d z=-2 t d t$, Eq. (7) is

$$
W_{h}=w_{w}\left(\frac{k_{c}}{w_{w}}+k_{\phi}\right) \sqrt{D} \int_{0}^{\sqrt{z_{0}}}\left(z_{0}-t^{2}\right)^{n} d t
$$

Expanding $\left(z_{0}-t^{2}\right)^{n}$, and using the first two terms $\left(z_{0}^{n}-n z_{0}^{n-1} t^{2}\right)$, Eq. (8) is as follows:

$$
W_{h}=\frac{w_{w}\left(\frac{k_{c}}{w_{w}}+k_{\phi}\right) \sqrt{z_{0} D}}{3} z_{0}^{n}(3-n)
$$

Rearranging Eq. (9) it becomes,

$$
z_{0}=\left[\frac{3 W_{h}}{w_{w}(3-n)\left(\frac{k_{c}}{w_{w}}+k_{\phi}\right) \sqrt{D}}\right]^{[2 /(2 n+1)]}
$$

Equation 10 indicates the sinkage of a wheel depends on its vertical load [9].

\section{Estimation method for the steady-state sinkage of the locked-wheel}

This study applies the wheel-soil interaction model defined by Bekker to estimate the steady-state sinkage of the locked-wheel, especially using Eq. (10). When the wheel is towed, the wheel moves dynamically. However, previous studies indicated that the resistance force acting on a plate from soil has weak velocity dependency when the velocity is small $[13,14]$. Although the wheelsoil interaction model is constructed based on the pressure-sinkage relationship, when the velocity is small, the phenomenon can be assumed close to a static. Thus, this paper postulates the wheel-soil model can be applied to the locked-wheel.

\section{Estimation method for the maximum resistance force of the locked-wheel}

The method was based on an observation by Wong [9]. As mentioned eariler, Wong's observation assumed that soil wedge area $A$ behaved like a plate and acted on soil mass area $B$. This paper, therefore, assumes that the soil wedge area $A$ move together with wheel and pushes soil wedge area $B$, and the slipsurface beneath the soil wedge is a constant shape. This section describes each force acting on the locked-wheel as shown in Fig. 3.

\section{Classical analytical model for calculating force $F_{1}$ against area $B$}

There are several analytical models for predicting force of plate tools against soil mass have been widely studied since 
the 1960s [15-20]. Analytical models have been developed for estimating or calculating earthmoving, excavation, and cutting force of a bucket. These models were summarized by [21], and the models have been verified by several types of research [22-24]. Furthermore, Yeomans et al. and Scott et al. $[14,25]$ proposed the leg model for planetary rovers and estimated its resistance force using these analytical models.

The analytical model for applying to the locked-wheel model requires the ability to consider the accumulated soil behind the wheel. The analytical models, however, have different abilities depending on the model. According to Blouin et al. [21], Osman, Mckyes, Grisso, Swick and Perumpral, and Zeng [15, 17-20] model can consider the accumulated soil. Osman model, however, contains indeterminate parameter referring to [22], and Mckeys and Swick \& perumpral model represents equivalent results according to [23].

Furthermore, our previous plate bulldozing tests confirmed that Mckyes model indicates a close value to the experiments. Form this result, we chose Mckyes model for calculating force $F_{1}$ in this paper.

\section{Mckyes model}

In 1985, Mckyes et al. [17] proposed the earthmoving model that was first introduced by Reece [26]. Mckyes model can consider the effects of the soil-tool adhesion $C_{a}$, soil cohesion $c$, soil weight $W_{b}$, blade width $w_{w}$, and surcharge $q$. The model assumes that the soil slip on the tool surface and within the soil itself. Then, the frictional component of shear strength on the two slip lines have been combined with perpendicular forces to form resultant forces $F_{T}$ and $R$, and cohesional resistance forces $C_{a} L$ and $c L_{1}$ as shown in Fig. 6 [17]. The total force $F_{T}$ acting on the plate is derived using Terzaghi's soil bearing capacity factor $N$ as follows:

$$
\begin{aligned}
& F_{T}=\left(\gamma g z_{0}^{2} N_{r}+c z_{0} N_{c}+q z_{0} N_{q}+C_{a} z_{0} N_{c a}\right) w_{w} \\
& N_{r}=\frac{(\cot \beta+\cot \rho)}{2[\cos (\beta+\delta)+\sin (\beta+\delta) \cot (\rho+\phi)]} \\
& N_{c}=\frac{(1+\cot \rho \cot (\rho+\phi))}{\cos (\beta+\delta)+\sin (\beta+\delta) \cot (\rho+\phi)} \\
& N_{q}=2 N_{\gamma} \\
& N_{c a}=\frac{1-\cot \beta \cot (\rho+\phi)}{[\cos (\beta+\delta)+\sin (\beta+\delta) \cot (\rho+\phi)]}
\end{aligned}
$$

where $\beta$ is the rake angle. $g$ is the earth gravity. $\rho$ is the shear plane failure angle. $\phi$ is the internal friction angle. $\gamma$ is the soil density. $\delta$ is the external friction angle. $q$ is the soil surcharge. Herein, this paper assumes that the soil surcharge $q$ is constant along the wheel width, and $\rho$ is generally found based on the assumption that the soil failure will occur at the angle $\rho$ which give the weakest resistance force. This can be estimated by determining the value of $\rho$ at which $N_{r}$ is minimized.

$$
F_{T h}=F_{T} \sin (\beta+\delta)
$$

where $F_{T h}$ represents the horizontal force of the total force $F_{T}$ acting to the plate. Herein, force $F_{T h}$ indicates $F_{1}$ of area $B$ (Fig. 3). This force can be generated by acting soil mass of area $A$, like a plate. The parameters used for the analytical model as shown in list of notations (Table 1).

\section{Shear and friction force $F_{2}, F_{3}, F_{5}$ of area $A$}

In area $A$, shear strength $F_{2}$ beneath the soil wedge is derived from Coulomb's failure criterion, and side friction force $F_{3}$ is calculated based on earth pressure at rest coefficient as follows:

$$
F_{2}=c w_{w} l_{s}+\left(W_{s}+W_{h}\right) \tan \phi
$$

where $W_{s}$ is the soil weight of the soil wedge and $W_{h}$ is the wheel weight. For the side friction force calculation, vertical normal stress at depth $z_{0}$ is:

$$
\sigma_{v}=\gamma g z_{0}+\sigma_{b}
$$

where $\sigma_{b}$ is the wheel weight per unit area. Then, the horizontal normal stress is:

$$
\sigma_{h}=K_{0} \sigma_{v}
$$

where $K_{0}=1-\sin \phi$ [27] is the coefficient of earth pressure at rest. Side friction force $F_{3}$ is derived as follows:

$$
F_{3}=2\left(c+\sigma_{h} \tan \phi\right) A_{\text {area }}
$$

where $A_{\text {area }}$ is an area of the side surface of the soil wedge in area $A$.

The frictional force $F_{5}$ is determined by the shear stress $\tau$, which is calculated based on Mohr-Coulomb model, in the tangential direction at an arbitrary point on the wheel surface as follows [12]:

$$
\tau=c_{w}+\sigma \tan \delta
$$

where $\sigma$ is the normal pressure on the wheel surface. $c_{w}$ is the soil-wheel adhesion. $\delta$ is the tool-soil friction angle. Therefore, the sum of the horizontal component of the shear force $\tau \cos (\theta)$ along the wheel surface is the force $F_{5}$ between the wheel surface and soil as follows: 
Table 1 List of notations

\begin{tabular}{|c|c|}
\hline Description (unit) & Symbol \\
\hline Each area of soil wedge in area $A\left(\mathrm{~m}^{2}\right)$ & $A_{\text {area }}$ \\
\hline Cohesion of the soil $\left(\mathrm{N} / \mathrm{m}^{2}\right)$ & c \\
\hline Soil-tool adhesion $\left(\mathrm{N} / \mathrm{m}^{2}\right)$ & $C_{a}$ \\
\hline Soil-wheel adhesion $\left(\mathrm{N} / \mathrm{m}^{2}\right)$ & $c_{w}$ \\
\hline Diameter of the wheel $(\mathrm{m})$ & $D$ \\
\hline Total resistance force of the locked-wheel $(\mathrm{N})$ & $F_{\text {total }}$ \\
\hline Force against soil mass area $B(N)$ & $F_{1}$ \\
\hline Shear force beneath the soil wedge area $A(N)$ & $F_{2}$ \\
\hline Side friction force of the soil wedge area $A(N)$ & $F_{3}$ \\
\hline Side friction force of the side surface of the wheel $(\mathrm{N})$ & $F_{4}$ \\
\hline Friction force on the wheel surface $(\mathrm{N})$ & $F_{5}$ \\
\hline Total force acting on the plate $(\mathrm{N})$ & $F_{T}$ \\
\hline Horizontal component of the total force $(\mathrm{N})$ & $F_{T h}$ \\
\hline Earth gravity $\left(\mathrm{m} / \mathrm{s}^{2}\right)$ & $g$ \\
\hline Coefficient of earth pressure at rest ( - ) & $K_{0}$ \\
\hline Soil modulus of deformation depend on $c\left(N / m^{(n+1)}\right)$ & $k_{c}$ \\
\hline Internal friction angle modulus $\left(\mathrm{N} / \mathrm{m}^{(\mathrm{n}+2)}\right)$ & $k_{\phi}$ \\
\hline Tool length $(\mathrm{m})$ & 1 \\
\hline Slip surface length (m) & $L_{1}$ \\
\hline Base line length of the soil wedge in area $A(m)$ & $I_{s}$ \\
\hline Sinkage ratio $(-)$ & $n$ \\
\hline Terzahgi's soil bearing capacity factors ( - ) & $N_{\gamma}, N_{c}, N_{q}, N_{c a}$ \\
\hline Normal stress $\left.\left(\mathrm{N} / \mathrm{m}^{2}\right)\right)$ & $p$ \\
\hline Surcharge on the soil surface $\left(\mathrm{N} / \mathrm{m}^{2}\right)$ & 9 \\
\hline Surcharge loading $(\mathrm{N})$ & Q \\
\hline Resultant force acting on slip surface $(\mathrm{N})$ & $R$ \\
\hline Wheel radius $(\mathrm{m})$ & r \\
\hline Width of the plate or wheel $(\mathrm{m})$ & $b, w_{w}$ \\
\hline Weight of the plate $(\mathrm{N})$ & $W_{p}$ \\
\hline Weight of the soil wedge $(\mathrm{N})$ & $W_{s}, W_{b}$ \\
\hline Weight of the wheel $(\mathrm{N})$ & $W_{h}$ \\
\hline Position toward the horizontal direction of the wheel $(\mathrm{m})$ & $x$ \\
\hline Sinkage $(m)$ & $z_{0}, z$ \\
\hline Rake angle $\left(^{\circ}\right)$ & $\beta$ \\
\hline Soil density $\left(\mathrm{kg} / \mathrm{m}^{3}\right)$ & $\gamma$ \\
\hline External friction angle $\left(^{\circ}\right)$ & $\delta$ \\
\hline Contact angle $\left(^{\circ}\right)$ & $\theta$ \\
\hline Static contact angle $\left(^{\circ}\right)$ & $\theta_{s}$ \\
\hline Shear plane failure angle $\left(^{\circ}\right)$ & $\rho$ \\
\hline Normal stress acting on wheel surface $\left(\mathrm{N} / \mathrm{m}^{2}\right)$ & $\sigma$ \\
\hline Horizontal normal stress $\left(\mathrm{N} / \mathrm{m}^{2}\right)$ & $\sigma_{h}$ \\
\hline Wheel weight per unit area $\left(\mathrm{N} / \mathrm{m}^{2}\right)$ & $\sigma_{b}$ \\
\hline Vertical normal stress $\left(\mathrm{N} / \mathrm{m}^{2}\right)$ & $\sigma_{\vee}$ \\
\hline Shear stress on the wheel surface $(\mathrm{N} / \mathrm{m})$ & $\tau$ \\
\hline Internal friction angle $\left(^{\circ}\right)$ & $\phi$ \\
\hline
\end{tabular}

$$
F_{5}=w_{w} r \int_{0}^{\theta_{o}} \tau \cos (\theta) d \theta
$$

where $w_{w}$ is the wheel width. $r$ is the wheel radius, and $\theta_{o}$ indicates the wheel contact angle at the soil surface. The calculation is performed using the soil and wheel parameters Tables 2, 3

\section{Experiment}

Fig. 7 depicts the schematic view of the experimental setup for the towing test. The soil bin area is width, length, and high of $0.3,1.2$, and $0.18-0.2 \mathrm{~m}$, respectively, and Silica Sand No. 5 fills that area. The size of the wheel is set as a basis of the rover testbed (Fig. 1) [11]. For the towing test at different wheel sizes, the wheel size is 0.17 , $0.20,0.28$, and $0.35 \mathrm{~m}$ in diameter, $0.04,0.06,0.08$, and 0.1 $\mathrm{m}$ in width (Fig. 8). The wheel mass is from 1.0 to $2.5 \mathrm{~kg}$. Tables 2, 3 summarizes the experimental conditions, the soil parameters, and variables for calculating the resistance force. In this system, the wheel can move to a vertical direction freely; that is, the towing motion does not affect the vertical motion. The wheel sinkage depends on the vertical load of the wheel. The wheel unit connects to the towing unit via the towing rope. For investigating the effect of the towing velocity on the force, the towing speed is $0.00341,0.017,0.0341$, and $0.051 \mathrm{~m} / \mathrm{s}$. The rotational speed of the towing motor shaft is 100, 500, 1000, and $1500 \mathrm{rpm}$ by PID control, and the towing speed of the wheel unit becomes the abovementioned velocities. The Motion Capture System measures the displacement, and the force sensor also measures the resistance force of the wheel. Tables 4, 5 summarize the specification of each system. The experimental trials are 5-10 times in each condition. The detailed procedure is as follows:

- A leveling plate with spikes stirs up the soil at first. Then, the leveling plate smooths the soil surface along the sidewall of the soil box without compaction.

- The wheel slowly and carefully is set on the soil surface.

- The rope tows the wheel unit at each constant speed.

\section{Experimental result Raw data}

Figure 9 provides the actual image of the towing experiment. Figure 10 also shows the raw data of the typical experiment. Each graph indicates the sinkage and resistance force. As shown in Fig. 9, 10, the wheel sinks into the soil with an increasing sinkage, and the resistance 


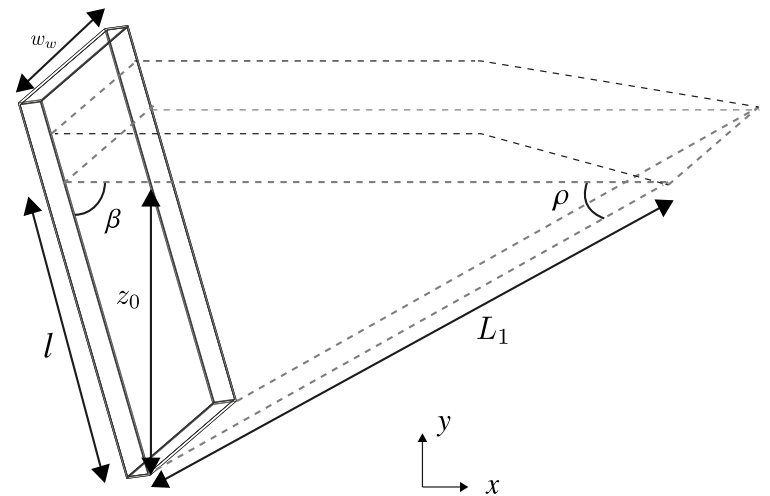

(a)

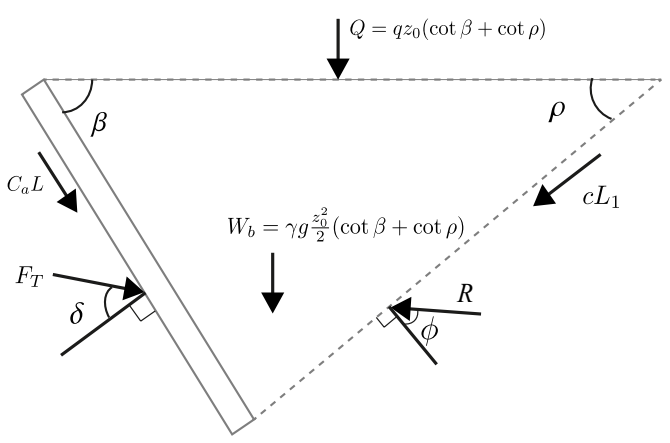

(b)

Fig. 6 The wedge theory of passive soil failure. a Soil wedge. $\mathbf{b}$ Forces on soil wedge

Table 2 Experimental conditions for the locked-wheel towing test

\begin{tabular}{|c|c|c|c|}
\hline Description (unit) & Value & & \\
\hline Slope angle $\left(^{\circ}\right)$ & 0 & & \\
\hline Soil & Silica Sand No. 5 & & \\
\hline Towing speed (m/s) & $\begin{array}{r}0.00341,0.017 \\
0.0341,0.051\end{array}$ & 0.00341 & \\
\hline $\begin{array}{l}\text { Rotational speed of } \\
\text { motor shaft (rpm) }\end{array}$ & $100,500,1000,1500$ & 100 & \\
\hline $\begin{array}{l}\text { Wheel diameter } \\
D(\mathrm{~m})\end{array}$ & 0.17 & 0.17 & $0.2,0.28,0.35$ \\
\hline Wheel width $w_{w}(m)$ & 0.04 & $0.06,0.08,0.1$ & 0.04 \\
\hline Wheel mass (kg) & $1.0,1.5,2.0,2.5$ & 2.5 & 2.5 \\
\hline
\end{tabular}

Table 3 Soil parameters and values for the calculation of the wheel force

\begin{tabular}{lllll}
\hline Modulus & Value & Unit & Name of parameters & References \\
\hline$c$ & 762 & $\left(\mathrm{~N} / \mathrm{m}^{2}\right)$ & Soil cohesion & {$[31]$} \\
$C_{a}$ & 762 & $\left(\mathrm{~N} / \mathrm{m}^{2}\right)$ & Soil-tool adhesion & {$[31]$} \\
$c_{W}$ & 0 & $\left(\mathrm{~N} / \mathrm{m}^{2}\right)$ & Soil-wheel adhesion & - \\
$g$ & 9.81 & $\left(\mathrm{~m} / \mathrm{s}^{2}\right.$ & Earth gravity & - \\
$k_{C}$ & 1000 & $\left(\mathrm{~N} / \mathrm{m}^{(\mathrm{n}+1)}\right.$ & Soil modulus of deformation depend on c & Decided by experiment \\
$k_{\phi}$ & 500000 & $\left(\mathrm{~N} / \mathrm{m}^{(\mathrm{n}+2)}\right.$ & Internal friction angle modulus & Decided by experiment \\
$n$ & 1.1 & $(-)$ & Sinkage ratio & Decided by experiment \\
$q$ & Measured & $\left(\mathrm{N} / \mathrm{m}^{2}\right)$ & Surcharge on the soil surface & Measured by experiment \\
$\delta$ & 15 & $\left({ }^{\circ}\right)$ & External friction angle & Decided by plate towing experiment \\
$\beta$ & 90 & $\left({ }^{\circ}\right)$ & Rake angle & - \\
$\gamma$ & 1430 & $\left(\mathrm{~kg} / \mathrm{m}^{3}\right)$ & Soil density & Measured by experiment \\
$\phi$ & 22.3 & $\left({ }^{\circ}\right)$ & Internal friction angle & [31] \\
\hline
\end{tabular}

force also rises. Then, the sinkage reaches a steady-state value.

\section{Velocity dependency}

Figure 11 shows the relationship between the resistance force and sinkage at different towing velocity. The difference between each value is small; therefore, the velocity dependency of the resistance force is weak under the towing velocities adopted in this paper.

\section{Sinkage at the steady-state condition}

Figures 12,13, 14 present the steady-state sinkage at different wheel mass, width, and diameter. The continuous lines indicate the theoretical results calculated by the sinkage model Eq. (10), and each plotted points indicates the experimental results of the sinkage at each steadystate condition.

The amount of sinkage increases with an increasing wheel mass, whereas it decreases with an increasing 
Table 4 Specification of motion capture system

\begin{tabular}{ll}
\hline Description (unit) & Value \\
\hline Model type $(-)$ & OptiTrack Prime13 \\
Frame rate (FPS) & 100 \\
Resolution (pixel) & $1280 \times 1024$ \\
Accuracy $(m)$ & $\leq 0.001$ \\
Operation range $(m)$ & $1-12$ \\
View angle $\left({ }^{\circ}\right)$ & Horizontal FOV:56, \\
& Vertical FOV:46 \\
\hline
\end{tabular}

Table 5 Specification of force sensor

\begin{tabular}{ll}
\hline Description (unit) & Value \\
\hline Model type $(-)$ & Leptrino \\
& PFS080YS102U6S \\
Rating capacity $F_{z}(\mathrm{~N})$ & \pm 1000 \\
Rating capacity $F_{x}, F_{y}(\mathrm{~N})$ & \pm 500 \\
Rating capacity $M_{x}, M_{y}, M_{z}(\mathrm{Nm})$ & \pm 30 \\
Sampling frequency $(\mathrm{Hz})$ & 100 \\
Resolution $(-)$ & $\pm 1 / 4000$ \\
\hline
\end{tabular}

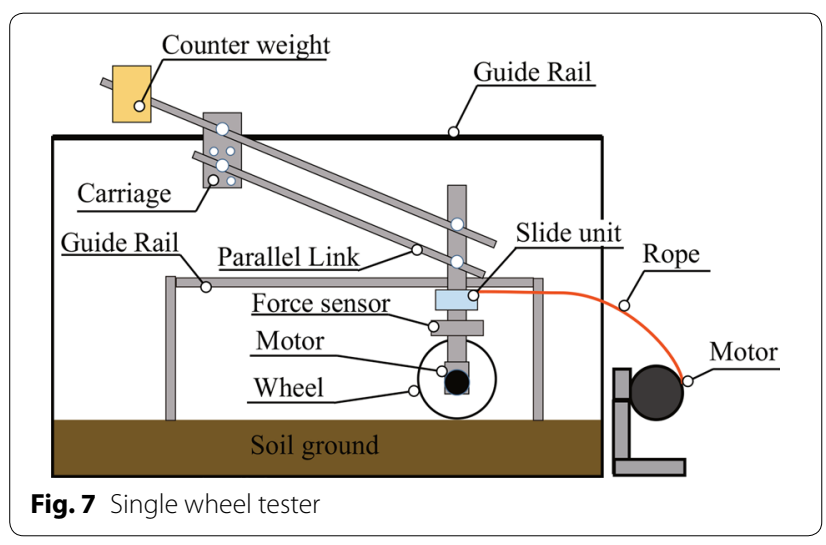

wheel width and diameter. This is because when the wheel width and diameter increases, the ground contact area becomes large. Consequently, the amount of sinkage can be reduced. The calculated results capture relatively the same trend as the experimental results.

\section{Resistance force at the steady-state condition}

Figures 15, 16, 17 also provide the resistance force at different wheel mass, diameter, and width. The continuous line indicates the theoretical value calculated by the resistance force model Eq. (1) and the data points indicate the resistance force when the sinkage becomes a steady-state value.

The resistance forces of the experimental results increase with an increasing wheel mass, whereas when the wheel diameter and width increase, the trend of the resistance force indicates a relatively decreasing trend as shown in the graphs Figs. 16, 17. The decreasing trend can be considered to be caused by decreasing the steadystate sinkage with an increasing wheel width and diameter. Although the theoretical value captures the trend of the resistance force depending on the wheel mass and diameter, the trend of the resistance force depending on the wheel width is relatively different. Furthermore, the change of the resistance forces depending on the wheel width and diameter is relatively small.

\section{Discussion}

Steady-state sinkage and resistance force

of the locked-wheel

According to Sybel et al. [7], the sinkage increased with an increasing distance where a wheel was towed, and the sinkage and force finally reached to a steady-value. The same increasing trend was confirmed as shown in Fig. 10. Additionally, experimental results in this paper confirmed that the steady-state sinkage depended on the contact area and wheel mass (Figs. 12, 13, 14), and the maximum resistance force depended on this sinkage (Fig. 15, 16, 17). Although the sinkage becomes large, the wheel mass especially contributes to improving the resistance force. When the wheel width and diameter increases, the contact area becomes large. However, the amount of sinkage decreases. Consequently, the change of the resistance force at steady-state sinkage depending on the wheel width and diameter can be considered small. To decide the required resistance force and the allowable steady-sinkage, this information can help to estimate the traveling performance of push-pull locomotion.

\section{Estimation model of the steady-state sinkage and resistance force}

Previous studies mainly confirmed the sinking behavior and resistance force experimentally [7, 9, 10, 28]. Andrade et al. [8] developed the estimation model of the resistance force especially for the locked-wheel of the Mrasokhod rover. However, theoretical consideration between the steady-state sinkage and maximum resistance force at different wheel size has remained unclear.

From experimental results, the velocity dependency of the resistance force was weak under the velocity adopted in this paper. Previous studies confirmed that the dependence of the plate force on the velocity at the low-speed range 1 or $10-50 \mathrm{~mm} / \mathrm{s}[13,14]$ was weak. Additionally, the dependence of the towing speed at $20-180 \mathrm{~cm} / \mathrm{s}$ for the plate force was confirmed small effect [29]. The experimental results indicated the same trend as the previous studies and suggested that the velocity dependency on the resistance force of the 


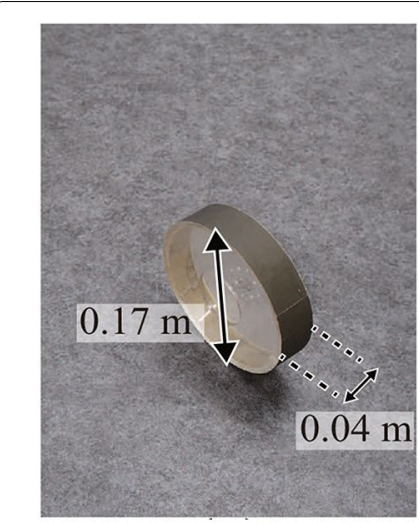

a

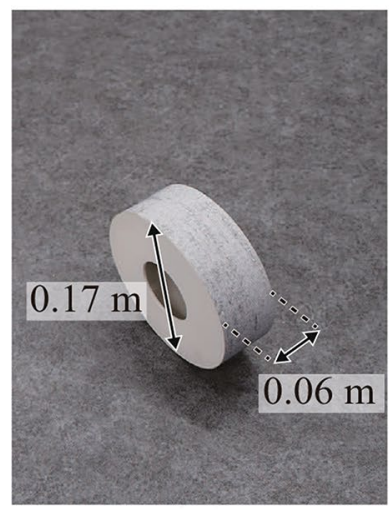

e

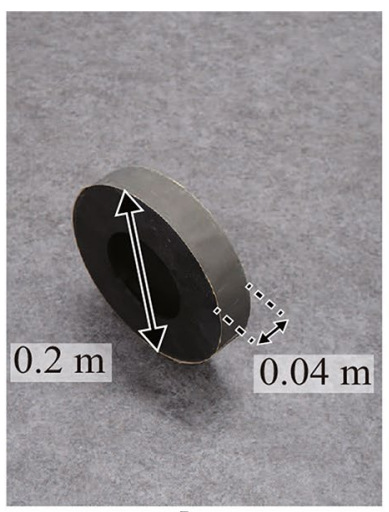

b

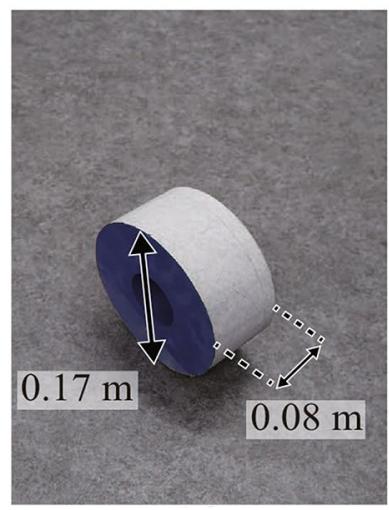

f

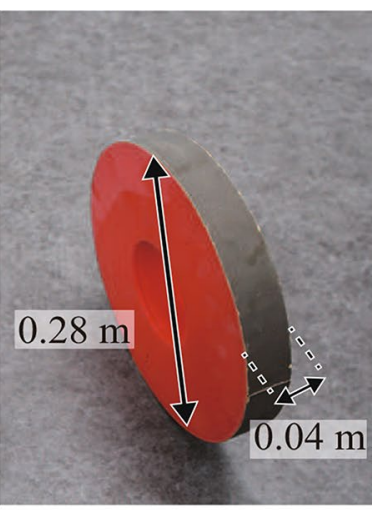

c

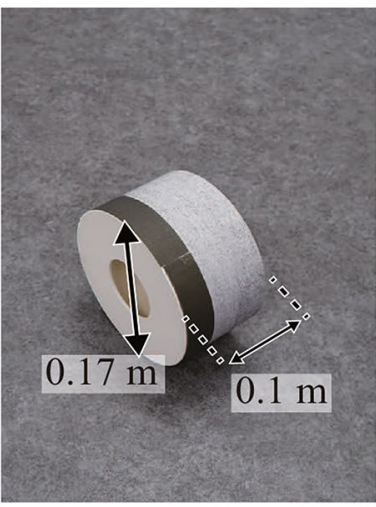

g

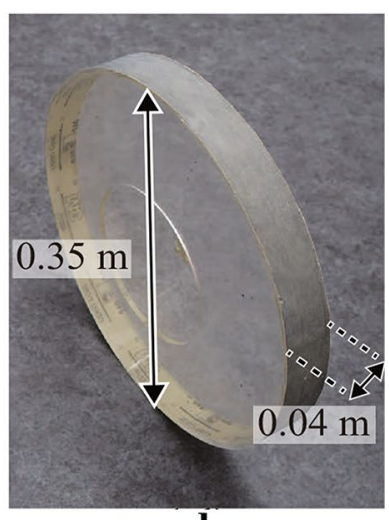

d

Fig. 8 Each wheel for the test. a Diameter $0.17 \mathrm{~m}$, width $0.04 \mathrm{~m}$, b Diameter $0.2 \mathrm{~m}$, width $0.04 \mathrm{~m}$, c Diameter $0.28 \mathrm{~m}$, width $0.04 \mathrm{~m}$. d Diameter 0.35 m, width $0.04 \mathrm{~m}$. e Diameter $0.17 \mathrm{~m}$, width $0.06 \mathrm{~m}$. f Diameter $0.17 \mathrm{~m}$, width $0.08 \mathrm{~m}$. g Diameter $0.17 \mathrm{~m}$, width $0.1 \mathrm{~m}$

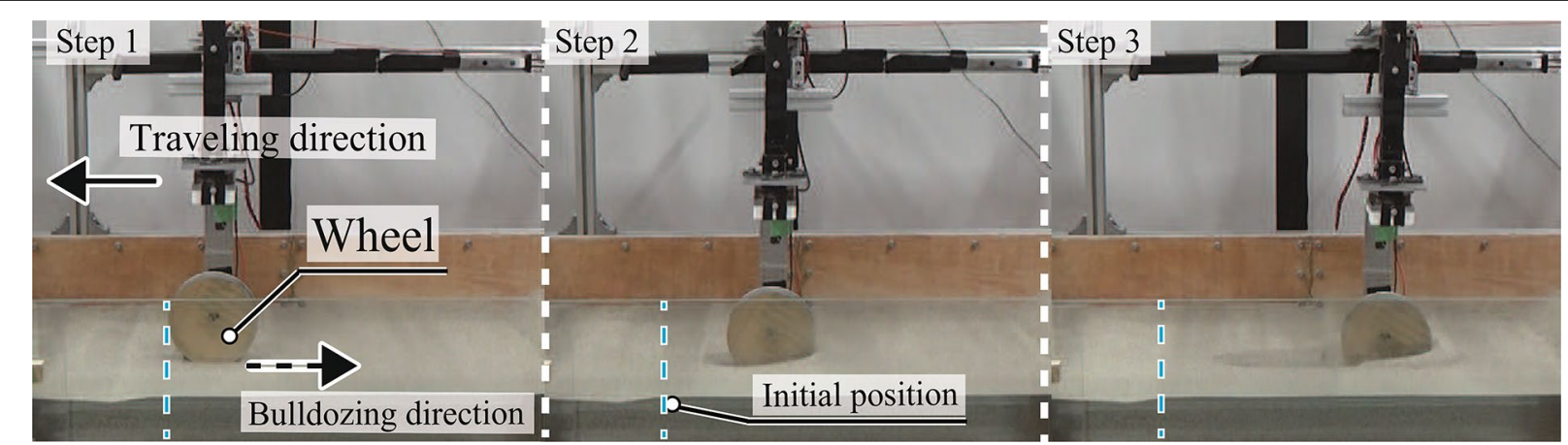

Fig. 9 Actual image of the wheel towing experiment. Diameter $0.17 \mathrm{~m}$; width $0.04 \mathrm{~m}$; mass $2.5 \mathrm{~kg}$

locked-wheel was weak. From this, the pressure-sinkage relationship of the locked-wheel can be considered as a static phenomenon under the towing velocity in this paper. This result suggested that the wheel-soil interaction model defined by Bekker can be applied to estimate sinkage of the locked-wheel.
The theoretical calculation for the steady-state sinkage based on terramchanics theory represented the same trend as the experimental results of the steadystate sinkage at different wheel mass, diameter, and width (Figs. 12, 13, 14, 15, 16, 17). This result suggested 


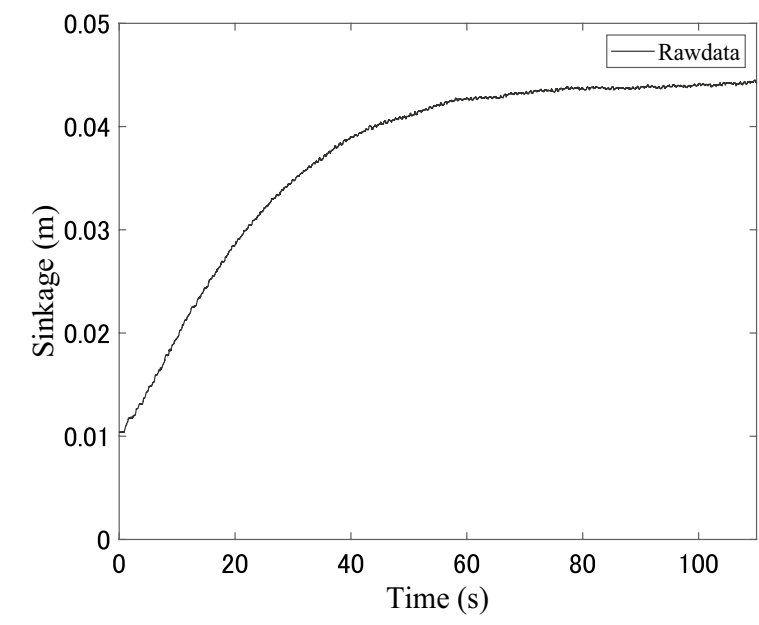

a

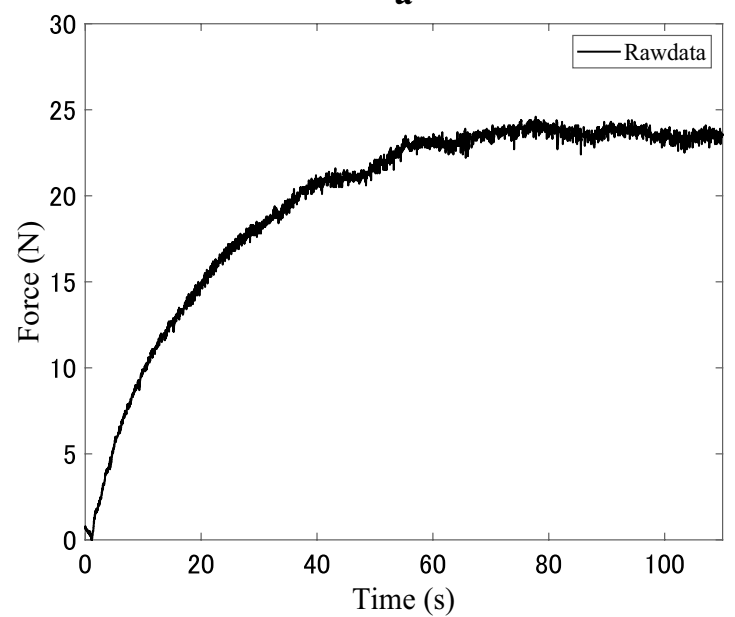

b

Fig. 10 Raw data of the sinkage and resistance force. Diameter 0.17 m; width $0.04 \mathrm{~m}$; initial sinkage $0.01 \mathrm{~m}$; wheel mass $2.5 \mathrm{~kg}$; towing speed $0.00341 \mathrm{~m} / \mathrm{s}$. a Sinkage, b Resisatnce force

that the model can be used for estimating the steadystate sinkage of the locked-wheel.

Although the trend of resistance force at different wheel width calculated by Eq. (1) relatively differed from the experimental results (Fig. 16), the theoretical result at different wheel diameter and mass indicated relatively the same trend of the experimental results (Figs. 15, 17).

The model indicated Eq. (1) includes some assumption. For example, the accumulated soil toward the towing direction was assumed uniform. However, our previous observation confirmed that the shape of an embankment behind the wheel along the wheel's width direction is nonuniform, like a fan-shaped.

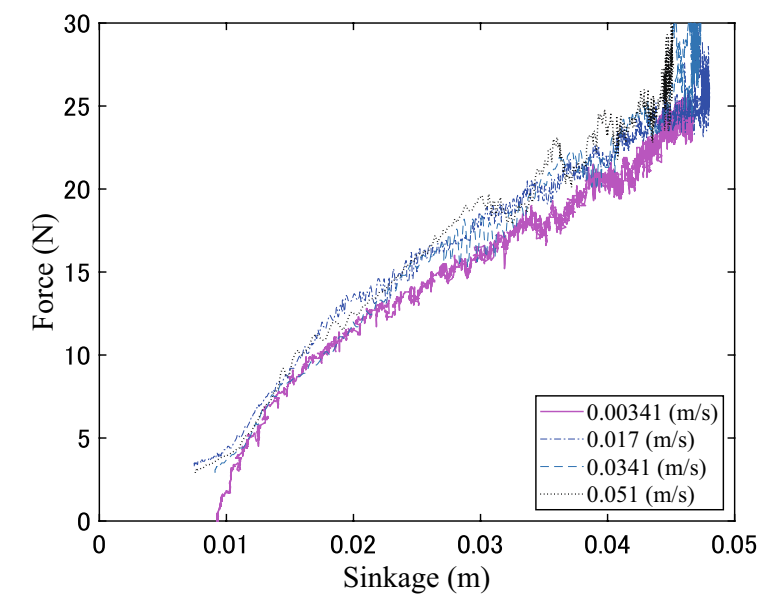

Fig. 11 Relationship between the wheel sinkage and resistance force at the different towing velocity

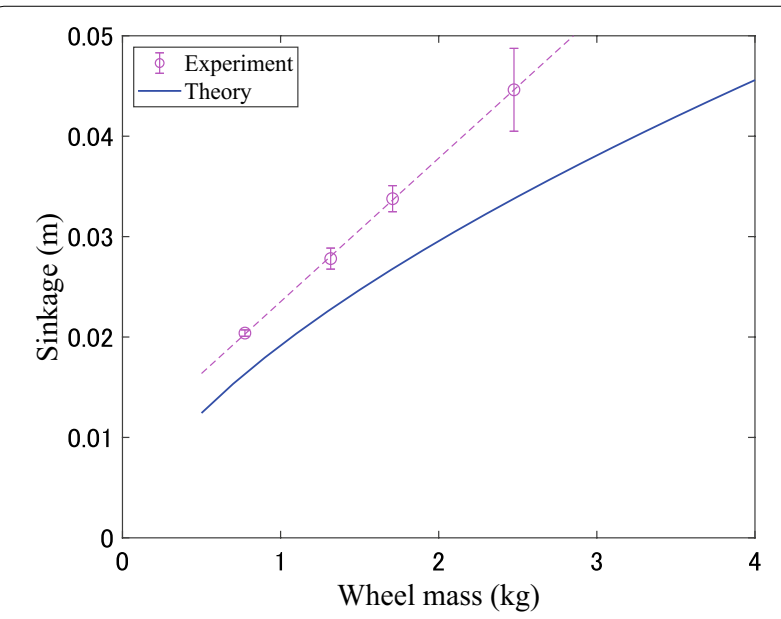

Fig. 12 Mean $\pm S D$ steady-state sinkage at different wheel mass. Diameter $0.17 \mathrm{~m}$; width $0.04 \mathrm{~m}$

Furthermore, Higa et al. [30] indicated that the stress distribution beneath the wheel along the wheel's width direction was also nonuniform. That is, the phenomenon and geometry in the soil wedge along the wheel width direction can be present nonuniform.

Furthermore, the theoretical model assumed a virtual plane between the soil wedge area $A$ and $B$ and assumed a constant slip surface beneath the soil wedge.

Further improvement in the locked-wheel model for steady-state values should consider the nonuniform phenomenon along the wheel width and validate assumption of the soil wedge, and slip surface. These considerations may allow an even closer value to the experimental values. 


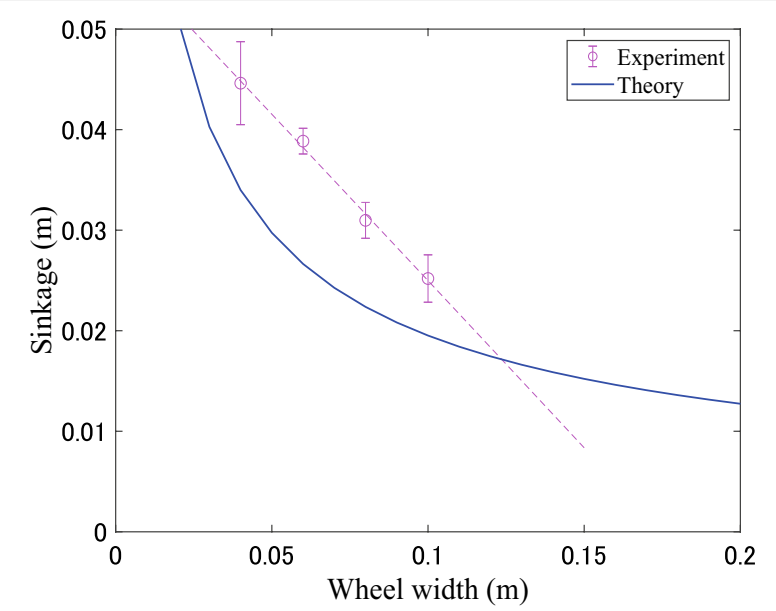

Fig. 13 Mean $\pm S D$ steady-state sinkage at different wheel width. Diameter $0.17 \mathrm{~m}$; mass $2.5 \mathrm{~kg}$

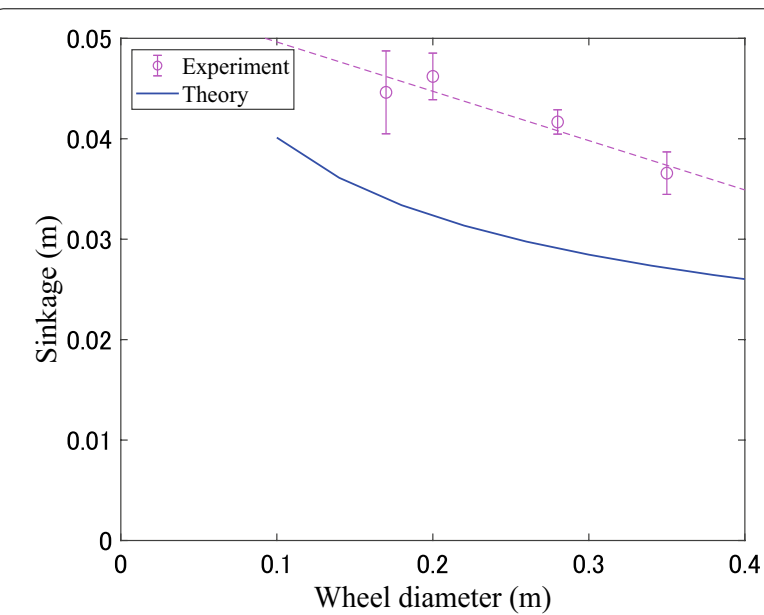

Fig. 14 Mean $\pm S D$ steady-state sinkage at different wheel diameter. Width $0.04 \mathrm{~m}$; mass $2.5 \mathrm{~kg}$

\section{Conclusion}

Locked-wheel behavior is a key factor for designing a push-pull locomotion rover. Understanding steadystate sinkage and its resistance force lead to understanding the maximum force that the locked wheel can generate. For this reason, this paper investigated the relationship between steady-state sinkage and the resistance force of the locked-wheel at different wheel mass, diameter, and wide. Additionally, we estimated the steady-state sinkage using the wheel-soil interaction model based on terramechanics at first, then tried to estimate the resistance force against its sinkage using the locked-wheel model based on soil mechanics. The experimental results clarified the steady-state sinkage and resistance force at different wheel sizes.

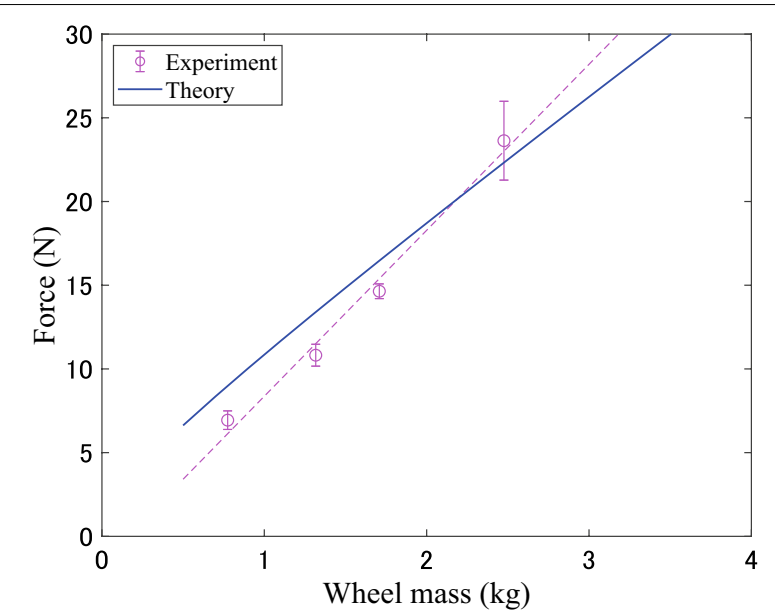

Fig. 15 Mean $\pm S D$ resistance force of steady-state sinkage at different wheel mass. Diameter 0.17 m; width $0.04 \mathrm{~m}$

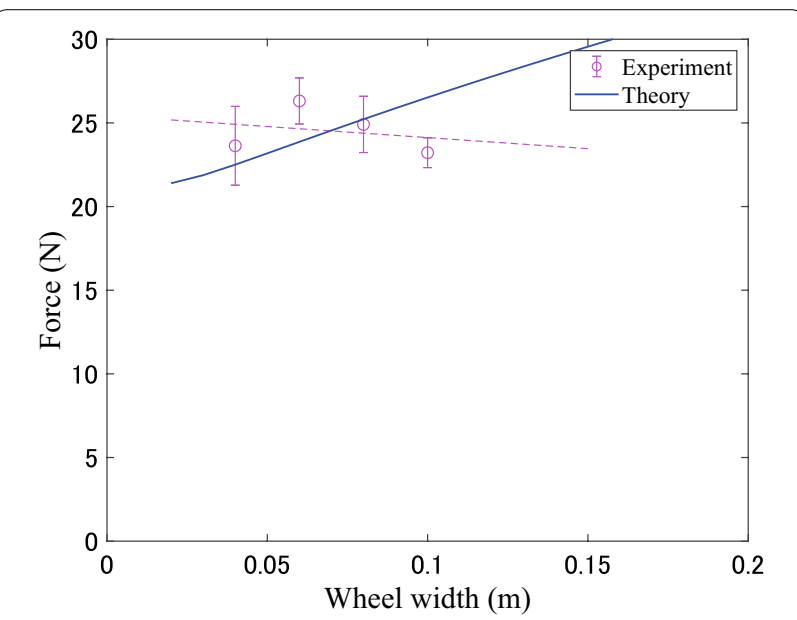

Fig. 16 Mean $\pm S D$ resistance force of steady-state sinkage at different wheel width. Diameter $0.17 \mathrm{~m}$; mass $2.5 \mathrm{~kg}$

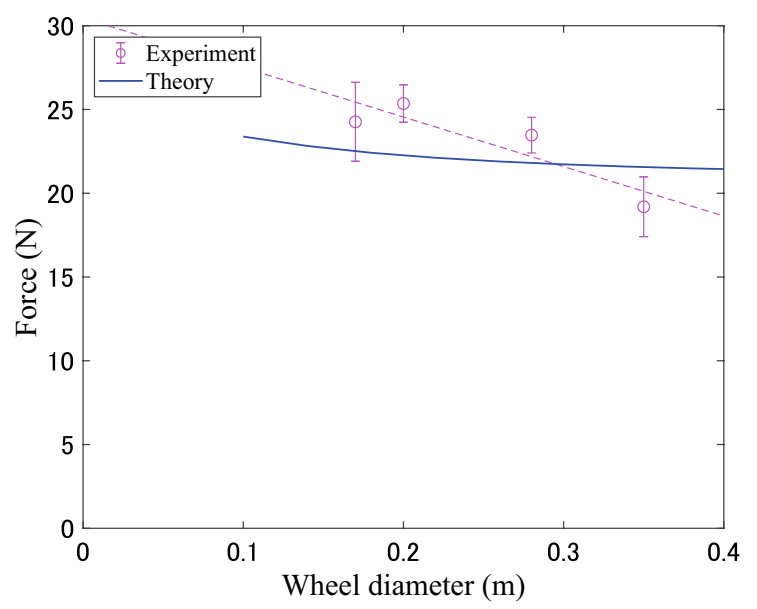

Fig. 17 Mean $\pm S D$ resistance force of steady-state sinkage at different wheel diameter. Width $0.04 \mathrm{~m}$; mass $2.5 \mathrm{~kg}$ 
Furthermore, the estimation of the sinkage and resistance force gave theoretical consideration. The main conclusions are as follows:

- The steady-state sinkage depends on the contact area and mass of the locked wheel. As the width and diameter increases, the steady-state sinkage becomes small, whereas when the width and diameter become small, the sinkage also becomes large. As the mass increases, the stady-state sinkage also increases.

- The maximum resistance force especially depends on the steady-state sinkage. Although the sinkage becomes large, increasing the wheel mass contributes to an increasing resistance force. Additionally, as an increasing wheel width and diameter, the resistance force becomes small because of decreasing the steady-state sinkage.

- The wheel-soil interaction model based on terramechanics captured relatively the same trend as the steady-state sinkage of the experimental results. Although the further consideration of the accuracy of the model and validating assumptions included in the model are necessary, the resistance force model using steady-state sinkage indicated relatively the same trend as the experimental results at different wheel diameter and mass.

This knowledge can contribute to the design for the traveling performance of push-pull locomotion. Furthermore, when the accurate model of the locked-wheel will be constructed through further consideration, the model can be used for unmanned control of the rovers. Further works comprise validating the accuracy of each model, considering the gravity effect, analyzing the behavior of the locked-wheel on any soil types such as regolith simulant of the planet, and constructing the push-pull locomotion model that uses the locked wheel model for autonomous control.

\section{Acknowledgements}

This work was supported by JKA and its promotion funds from KEIRIN RACE.

\section{Authors' contributions}

DF developed the methodology of the resistance force model and performed experiments and analyzed data. DF also drafted the manuscript. NT developed the methodology of estimating the steady-state sinkage. TO developed the towing experimental system. Kl edited and revised manuscripts. All authors read and approved the final manuscript.

\section{Funding}

The development of the experimental system, rover system, and analysis of this study were funded by JKA.

\section{Availability of data and materials}

The datasets used and analyzed in this study are available from the corresponding author upon request.

\section{Competing interests}

The authors declare that they have no competing interests.

\section{Author details}

${ }^{1}$ Department of Functional Control Systems, Shibaura Institute of Technology, 307, Fukasaku, Minuma-ku, Saitama 337-8570, Japan. ${ }^{2}$ Department of Machinery and Control Systems, Shibaura Institute of Technology, 307, Fukasaku, Minuma-ku, 337-8570 Saitama, Japan.

Received: 21 April 2020 Accepted: 3 October 2020

Published online: 27 October 2020

\section{References}

1. NASA (2020) NASA MARS 2020 Mission. https://mars.nasa.gov/mars2020/. Accessed 15 Apr 2020

2. Orosei R, Lauro SE, Pettinelli E, Cicchetti A, Coradini M, Cosciotti B, Di Paolo F, Flamini E, Mattei E, Pajola M, Soldovieri F, Cartacci M, Cassenti F, Frigeri A, Giuppi S, Martufi R, Masdea A, Mitri G, Nenna C, Noschese R, Restano M, Seu R (2018) Radar evidence of subglacial liquid water on mars. Science 361(6401):490-493. https://doi.org/10.1126/science.aar72 68

3. ESA (2020) ESA ExoMars mission 2022. http://www.esa.int/Science_Explo ration/Human_and_Robotic_Exploration/Exploration/ExoMars. Accessed 15 Apr 2020

4. JAXA (2020) JAXA Hayabusa2. http://www.hayabusa2.jaxa.jp/. Accessed 15 Apr 2020

5. Tsuda Y, Yoshikawa M, Saiki T, Nakazawa S, ichiro Watanabe S (2019) Hayabusa2-sample return and kinetic impact mission to near-earth asteroid ryugu. Acta Astronautica 156:387-393. https://doi.org/10.1016/j. actaastro.2018.01.030

6. Azkarate M, Zwick M, Hidalgo Carrió J, Nelen R, Wiese T, Poulakis P, Joudrier L, Visentin G (2015) First experimental investigations on wheelwalking for improving triple-bogie rover locomotion performances. In: Conference: ASTRA 2015-13th ESA Workshop on Advanced Space Technologies for Robotics and Automation, At Noordwijk, The Netherlands

7. Sybel HV, Grosse-Scharmann F (1961) Triebkraftsteigerung bei geländefahrzeugen durch das schub-scritt-verfahren (increasing of driving forces in terrain through push-walk process). In: Proc First International Conference on Terrain-Vehicle Systems, Edizioni Minerva Techinca, pp 895-912

8. Andrade G, Amar FB, Bidaud P, Chatila R (1998) Modeling robot-soil interaction for planetary rover motion control. In: Proceedings. 1998 IEEE/RSJ International Conference on Intelligent Robots and Systems. Innovations in Theory, Practice and Applications (Cat. No.98CH36190), vol 1, pp 576 581. https://doi.org/10.1109/IROS.1998.724680

9. Wong J (1978) Theory of ground vehicles. Wiley, New Jersey

10. Creager C, Johnson K, Plant M, Moreland S, Skonieczny K (2015) Push-pull locomotion for vehicle extrication. J Terramech 57:71-80. https://doi. org/10.1016/j.jterra.2014.12.001

11. Fujiwara D, lizuka K, Asami D, Kawamura T, Suzuki S (2019) Study on traveling performance for variable wheel-base robot using subsidence effect. Int J Mech Eng Robotics Res. https://doi.org/10.18178/ijmerr.8.2.233-238

12. Bekker G (1969) Introduction to terrain-vehicle systems. University of Michigan Press, Ann Arbor

13. Albert R, Pfeifer MA, Barabási AL, Schiffer $P$ (1999) Slow drag in a granular medium. Phys Rev Lett 82:205-208. https://doi.org/10.1103/PhysRevLet t.82.205

14. Yeomans B, Saaj CM, Winnendael MV (2013) Walking planetary roversexperimental analysis and modelling of leg thrust in loose granular soils. J Terramech 50(2):107-120. https://doi.org/10.1016/j.jterra.2013.01.006

15. Osman MS (1965) The mechanics of soil cutting blades: osman, m.s., jour. agric engr res, 9, 4, 1965. J Terramech 2(1):98. https://doi. org/10.1016/0022-4898(65)90115-1

16. Gill WR, Vanden Berg GE (1967) Soil dynamics in tillage and traction. Washington, D.C. : Agricultural Research Service, U.S. Dept. of Agriculture, includes index

17. McKyes E (1985) Soil cutting and tillage. Developments in agricultural engineering. Elsevier Science, Amsterdam 
18. Grisso R, Perumpral J (1985) Review of models for predicting performance of narrow tillage tool. Trans ASA. https://doi.org/10.13031 /2013.32388

19. Swick W, Perumpral J (1988) A model for predicting soil-tool interaction. J Terramech 25(1):43-56. https://doi.org/10.1016/0022-4898(88)90061-4

20. Zeng X, Burnoski L, Agui J, Wilkinson A (2007) Calculation of excavation force for isru on lunar surface. https://doi.org/10.2514/6.2007-1474

21. Blouin S, Hemami A, Lipsett M (2001) Review of resistive force models for earthmoving processes. J Aerospace Eng. https://doi.org/10.1061/ (ASCE)0893-1321(2001)14:3(102)

22. Wilkinson A, DeGennaro A (2007) Digging and pushing lunar regolith: classical soil mechanics and the forces needed for excavation and traction. J Terramecha 44(2):133-152. https://doi.org/10.1016/j.jterr a.2006.09.001

23. King R, Susante PV, Gefreh M (2011) Analytical models and laboratory measurements of the soil-tool interaction force to push a narrow tool through jsc-1a lunar simulant and ottawa sand at different cutting depths. J Terramecha 48(1):85-95. https://doi.org/10.1016/j.jterr a.2010.07.003

24. Xi B, Jiang M, Cui L, Liu J, Lei H (2019) Experimental verification on analytical models of lunar excavation. J Terramech 83:1-13. https://doi. org/10.1016/j.jterra.2019.01.002

25. Scott G, Saaj C (2012) The development of a soil trafficability model for legged vehicles on granular soils. J Terramech 49:133-146. https://doi. org/10.1016/j.jterra.2011.12.002
26. Reece AR (1964) Paper 2: the fundamental equation of earth-moving mechanics. Proceedings of the Institution of Mechanical Engineers, Conference Proceedings 179(6):16-22. https://doi.org/10.1243/ PIME_CONF_1964_179_134_02

27. Jaky J (1944) The coefficient of earth pressure at rest. in hungarian (a nyugalmi nyomas tenyezoje). J Soc Hungarian Arch Eng 78(22):355-358

28. Scott J Moreland DWCCVA Krzysztof Skonieczny (2011) Soil motion analysis system for examining wheel-soil shearing. In: 17th International Conference of the International Society for Terrain Vehicle Systems 2011 (ISTVS 2011), Blacksburg, Virginia

29. Wieghardt K (1975) Experiments in granular flow. Ann Rev Fluid Mech 7(1):89-114. https://doi.org/10.1146/annurev.fl.07.010175.000513

30. Higa S, Nagaoka K, Nagatani K, Yoshida K (2015) Measurement and modeling for two-dimensional normal stress distribution of wheel on loose soil. J Terramech 62:63-73. https://doi.org/10.1016/j.jterra.2015.04.001

31. Noriaki M (2013) Study on development locomotion performance based on terramechanics for wheeled rover on soft ground. PhD thesis, SOKENDAI

\section{Publisher's Note}

Springer Nature remains neutral with regard to jurisdictional claims in published maps and institutional affiliations.

\section{Submit your manuscript to a SpringerOpen ${ }^{\circ}$ journal and benefit from:}

- Convenient online submission

- Rigorous peer review

- Open access: articles freely available online

- High visibility within the field

- Retaining the copyright to your article

Submit your next manuscript at springeropen.com 